\title{
The Study of Non-isothermal Jets under the Influence of Buoyancy Flux
}

\author{
$\mathrm{Li} \mathrm{Bai}^{1, \text { a }}$, Yawei Hua ${ }^{2, b^{*}}$ and Weijuan Liü,c \\ ${ }^{1,2,3}$ School of Municipal \& Environmental Engineering, Jilin Jianzhu University, Changchun, China

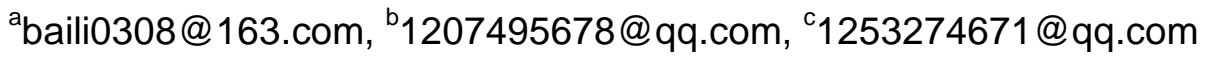

Keywords: buoyancy flux; non-isothermal Jets; axis offset; velocity attenuation; settlement of cold wind;

\begin{abstract}
Through analyzing numerical simulation about shutter tuyere non-isothermal Jets, the influence of buoyancy flux was studied in axis offset, axial velocity attenuation and the settlement of cold wind. The conclusion is that buoyancy flux promotes axis offset to a certain extent; buoyancy flux does not substantially change the axial velocity attenuation trend, but speeds up axial velocity attenuation; due to the buoyancy flux, air-conditioned room has settlement of cold wind, especially when temperature difference is sharp and the wind speed is small.
\end{abstract}

\section{Introduction}

Air supply outlet is the end device of air conditioning system. Jet effect of air supply outlet is the concern of engineering technical personnel, which directly affects temperature and velocity distribution in the room. For non-isothermal jet, main factors that influence the indoor air jet are mass flow, momentum flux, the shape of the air outlet and buoyancy flux. Buoyancy flux have a certain impact on the non-isothermal jets. For engineering practice, the influence of buoyancy flux on the jet flow is considered. At the same time, it can not exaggerate its influence, which needs to not only have a qualitative understanding of buoyancy flux, but also to do quantitative research. With the development of computer technology, computational fluid dynamics is applied to the design of air flow organization in various spaces. It is important significance to solve air distribution and environmental comfort in air-conditioned room through using numerical simulation method to study the characteristics of the non-isothermal jet and analysis the difference between non-isothermal jet and isothermal jet.

\section{Model Design}

Building Air-conditioned Room Model. A air-conditioned room was built with long $3200 \mathrm{~mm}$, wide $5600 \mathrm{~mm}$, high $7200 \mathrm{~mm}$. In order to study the influence of a single variable on the jet, the temperature of the retaining structure is constant and is consistent with the room temperature.

The Situation of Air Supply Outlet. Shutter and diffuser are the most common outlets in the field of air conditioning. In order to facilitate the establishment of air supply opening model and reduce the amount of simulation computation, the double shutter was selected in the experiment. Shutter size is $700 \mathrm{~mm} \times 160 \mathrm{~mm}$, and effective area coefficient is 0.72 .

Temperature Setting.The temperature of all of air-conditioned room was set to $20^{\circ} \mathrm{C}$, and the temperature of the air outlet was $9^{\circ} \mathrm{C}$ and $16^{\circ} \mathrm{C}$ respectively, which represented two air supply conditions of the large temperature difference and the small temperature difference. 


\section{Simulation Process}

The Selection of Equation Model. For the turbulent flow equation, the results of standard two equation model simulation can achieve the required accuracy of engineering in good agreement with the actual results ${ }^{[1,2]}$. Standard two equation model was used to simulate the turbulent jet and the indoor flow, which can avoid the error caused by the turbulence model, so as to analyze the influence of the buoyancy flux in the experiment.

The Simplification of Air Supply Outlet.Under the condition of constant length and width ratio, the model area of the air outlet is the product of the original area and the effective area coefficient ${ }^{[3]}$, which can ensure the mass flux and the momentum flux in accordance with reality.

The Situation of Grid Partition and Selection of Iteration Number. The method of unstructured grid partition was used for the experiment to improve the accuracy of the classification as much as possible and avoid the effect of the grid partition on the simulation results. In the three dimensions of length, width and height, all of the size of the maximum grid were set to $0.2 \mathrm{~m}$. The grid number was 16057, and the number of nodes was 169729 . The number of iterations has a great influence on the simulation results. If the number of iterations is too small to get the correct results, and if the number of iterations is too much, it will increase the computational time. The number of iterations was 300 times for calculation in this sample.

\section{The Analysis of Simulation Results}

The Situation of Axis Offset.The variation curve of the axis offset was plotted with range in different conditions of outlet velocity and temperature. As shown in Figure 1, the outlet velocity and temperature of curve $1 \sim 4$ were respectively $16^{\circ} \mathrm{C}, 5 \mathrm{~m} / \mathrm{s}, 9^{\circ} \mathrm{C}, 5 \mathrm{~m} / \mathrm{s}, 16^{\circ} \mathrm{C}, 2 \mathrm{~m} / \mathrm{s}$ and $9{ }^{\circ} \mathrm{C}, 2 \mathrm{~m}$ / s.

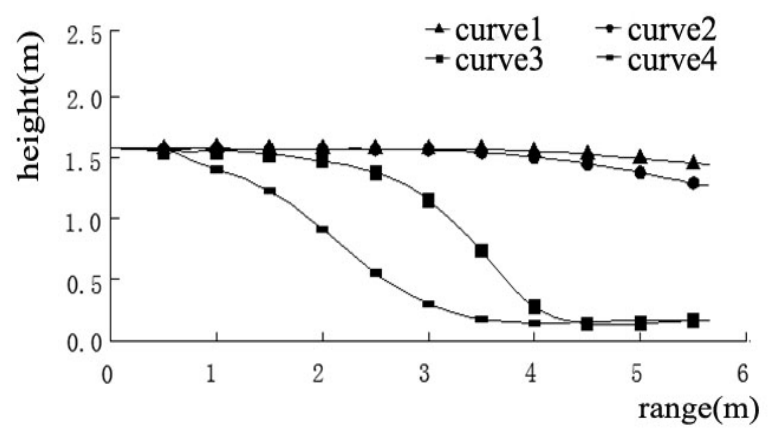

Figure 1 variation curve with range

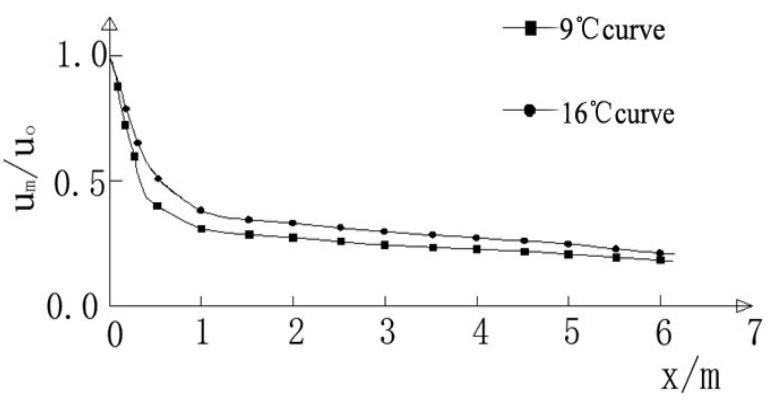

Figure 2 velocity attenuation curve

From Figure 1, whether large or small temperature difference in the speed of $5 \mathrm{~m} / \mathrm{s}$, axis offset was not obvious. The axial velocity varied greatly with the range at the speed of $2 \mathrm{~m} / \mathrm{s}$, especially under the condition of the large temperature difference, which obviously offsets when the distance was less than $1 \mathrm{~m}$. From the calculation formula for buoyancy flux ,the buoyancy flux is proportional to the temperature difference. According to the literature [4], the calculation formula for buoyancy flux is: 


$$
B=-g \frac{\Delta T}{T_{O}} L \rho
$$

In the formula, $g$ is the acceleration of gravity, $\mathrm{m} / \mathrm{s}^{2} ; \rho$ is the density of supply air, $\mathrm{kg} / \mathrm{m}^{3} ; \Delta T$ is the difference between the temperature of supply air $T$ and indoor temperature $T_{O}, \mathrm{k}$.

Axis Velocity Attenuation.The axial velocity of the jet decreased with increasing range. In order to study the influence of outlet temperature of jet, the dimensionless velocity attenuation was drawn, whose outlet temperature is $9{ }^{\circ} \mathrm{C}$ and $16^{\circ} \mathrm{C}$. As shown in Figure 2, the attenuation trend of the velocity attenuation curve with $9{ }^{\circ} \mathrm{C}$ and $16{ }^{\circ} \mathrm{C}$ was basically the same. Due to the influence of buoyancy flux, the axial velocity of $9^{\circ} \mathrm{C}$ decayed rapidly, basically, which was consistent with the description of literature [5].

The Situation of Settlement of Cold Wind.Because of the influence of buoyancy flux, it caused settlement of cold wind to a certain extent in air-conditioned room. The settlement of cold wind gave body a sense of discomfort ${ }^{[6]}$, but more importantly, it directly threatened the health of people in the air-conditioned room for a long time. In order to facilitate the observation of settlement of cold wind, it was simulated the distribution of the temperature in the vertical plane by four kinds of condition ( Outlet temperatures and the wind speeds were respectively $16^{\circ} \mathrm{C}, 5 \mathrm{~m} / \mathrm{s}, 9^{\circ} \mathrm{C}, 5 \mathrm{~m} / \mathrm{s}, 16^{\circ} \mathrm{C}, 2 \mathrm{~m} / \mathrm{s}$ and $9^{\circ} \mathrm{C}, 2 \mathrm{~m} / \mathrm{s}$ in condition $1 \sim 4$ ). As shown in Figure 3 6 below.

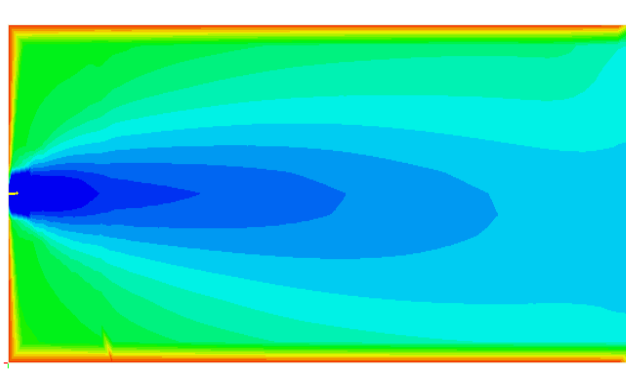

Figure 3 temperature distribution in the vertical plane of condition 1

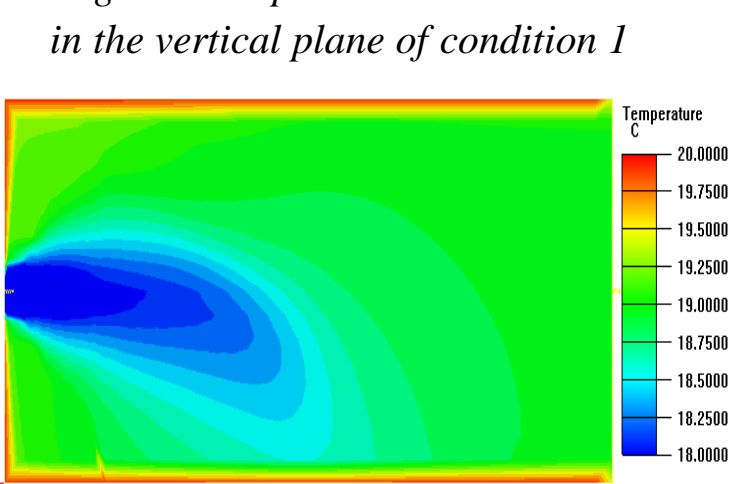

Figure 5 temperature distribution

in the vertical plane of condition 3

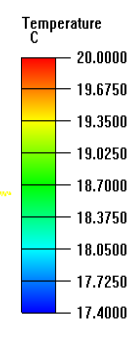

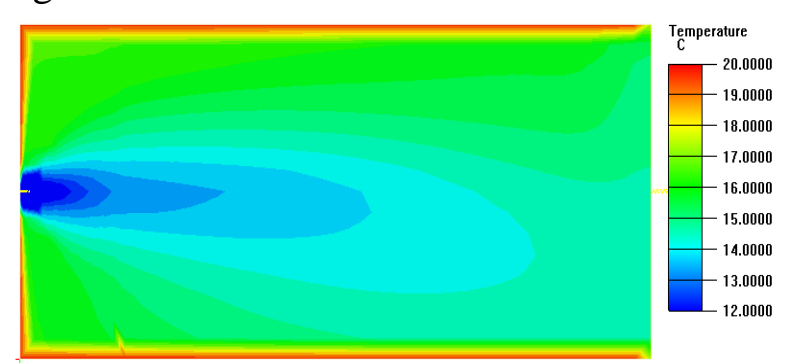

Figure 4 temperature distribution in the vertical plane of condition 2

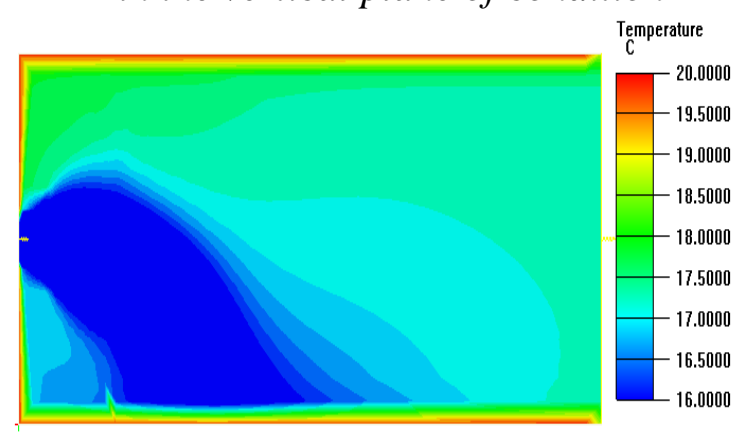

Figure 6 temperature distribution in the vertical plane of condition 4

From the figures of the temperature distribution, the lower the wind speed was, the more serious the settlement of cold wind was, and the temperature of air supply also affected it. Larger wind speed 
enhanced the air entrainment in the room, and extended the length of the jet at the outlet wind speed of $5 \mathrm{~m} / \mathrm{s}$. even in the case of large temperature difference at the outlet temperature of $9^{\circ} \mathrm{C}$, it would not cause that cold air flowed directly down to the human body. When outlet wind speed was $2 \mathrm{~m} / \mathrm{s}$, especially when the large temperature difference, due to the small jet momentum, buoyancy flux forced the jet downward deflection to make settlement of cold wind particularly serious. It was not conducive for mixing of cold and hot air flow and posed a threat to sense of comfort for air-conditioned room.

\section{Summary}

Buoyancy flux makes the jet axis downward drift. When the jet velocity is relatively small, it will make the jet axis has a large offset. The axial velocity attenuation trend of the large temperature difference air supply and the small temperature difference is basically the same. As the influence of the buoyancy flux, Air velocity in the large temperature difference is attenuated rapidly. When air velocity is larger, the settlement of cold wind will not be serious; when the air velocity is small, especially large temperature difference and little wind speed, it will produce serious phenomenon of settlement of cold wind, which should arouse the attention of related engineering technical personnel.

\section{Acknowledgements}

This work was financially supported by the National ' 125' Research Subject of State

\section{Science and}

Technology Support Program(2011BAJ 05B03).

\section{References}

[1] Nielsen P V. The selection of turbulence models for prediction of room airflow [J].ASH RAE Tranasactions, 1998, 104(1):1119-1126.

[2] HUA Yawei ,BAI Li, CHE Wenhao, Chang Wentao. Performance comparison of three kinds of turbulence models in numerical simulation of air jet[J]. Journal of Jilin Jianzhu University,2015,32 ( 1

), 51-54.

[3] Zhao Bin, Li Xianting, Yan Qisen. Numerical simulation of the air jet in the air shutter [J] Technical exchange Garden.2001, 31(6):86-89.

[4] Tritton D J. Physical Fluid Dynamics [M].Clarendon Press, Oxford,1988 .

[5] Li Rui, Kang Xiaopeng, Ding Tao, Yang Hui. Experimental study on low temperature jet of air conditioning air supply outlet of air conditioning [J]. Fluid machinery,2004 , 32 ( 4 ) :5-7.

[6] Chen Xiaochun, Zhu Yingxin. Study on Numerical Simulation of air flow in air conditioning ventilation room with zero equation model. [ J].HVAC, 2006, 36(8):18-24. 
International Forum on Energy, Environment Science and Materials (IFEESM 2015)

[7] Wu Xiping, Zhu Zhe. Study on the indoor air flow and comfort of cold air supply [ J]. East China Power,20008:16-18 
International Forum on Energy, Environment Science and Materials (IFEESM 2015) 